\title{
PEDAGOGIA DO OPRIMIDO - UM LEGADO GENEROSO E ESPERANÇOSO
}

\author{
MADERS, Sandra ${ }^{1}$ \\ BARCELOS, Valdo ${ }^{2}$
}

\begin{abstract}
RESUMO
Este artigo tem como objetivo principal fazer uma reflexão sobre a contribuição e a atualidade, para a educação brasileira, do clássico Pedagogia do Oprimido, de Paulo Reglus Neves Freire (1921-1997). Com Pedagogia do Oprimido, Freire fez um exercício intelectual fundamental: partiu da busca do entendimento da realidade vivida para construir a realidade sonhada. Sintetizou esse exercício ao dizer que a realidade não é assim, está assim. Mais uma vez, a atualidade de Pedagogia do Oprimido soa como um clamor a todos(as) que não se conformaram com as injustiças e "malvadezas" de grande parte das elites brasileiras. Freire nunca se deixou abater e apostou na esperança como força revolucionária e libertadora. A esperança em Freire não é uma esperança van. É um compromisso com a história vivida pelas "gentes" do Brasil. Essa esperança se fundamenta na crença de que homens e mulheres são seres "inconclusos" e, como tal, em permanente transformação de si e das suas realidades. Para Freire, a história é uma construção inacabada. Essa é uma das diferenças fundamentais entre uma educação "bancária" e uma educação problematizadora e libertadora. Enquanto a primeira busca a acomodação, a repetição; a segunda busca a reflexão, a ação, a problematização das dificuldades, a superação das barreiras interpostas por uma dada realidade. A superação dessas barreiras é o primeiro passo para a superação dos limites e realização do "inédito-viável" que propõe Freire.
\end{abstract}

PALAVRAS-CHAVE: Pedagogia do Oprimido; Paulo Freire; Realidade; Esperança.

\footnotetext{
${ }^{1}$ Professora Adjunta no curso de Ciências da Natureza Licenciatura/UNIPAMPA. Doutora e Mestre em Educação pela Universidade Federal de Santa Maria. Pedagoga. E-mail: sandraufsmppge@ gmail.com

${ }^{2} \mathrm{PhD}$ em Antropofagia Cultural Brasileira. Professor Titular Universidade Federal de Santa Maria/UFSM. RS. Email: vbarcelos@terra.com.br
} 


\title{
e-Curriculum
}

\section{PEDAGOGY OF THE OPPRESSED - A GENEROUS AND HOPEFUL LEGACY}

\author{
MADERS, Sandra ${ }^{4}$ \\ BARCELOS, Valdo ${ }^{5}$
}

\begin{abstract}
This article has as its main goal to reflect on the contribution and the present situation, for the Brazilian education, of the classic Pedagogy of the Oppressed from Paulo Reglus Neves Freire (1921-1997). With Pedagogy of the Oppressed Freire does a fundamental intellectual exercise: he went from the search of understanding the living reality to building the dreamed reality. He synthesized this exercise by stating that the reality is not settled, that it is a state of the moment. Once again, the sense of present time of Pedagogy of the Oppressed sounds as a calling to all of those who did not resign themselves to the injustices and the "meanness" of great part of the Brazilian elite. Freire never let himself to be put off and he bet on the hope as a revolutionary and freeing form of strength. The hope on Freire is not an empty hope. It is a commitment with the history lived by the Brazilian people. This hope is based on the belief that men and women are not complete beings, and so they are in permanent transformation of themselves and their realities. To Freire, the history is a non-ending construction.This is one of the fundamental differences between a "banking" education and a freeing and problematizing education. While the first one seeks for settling and repetition, the second one seeks for reflection, action, problematization of difficulties, overcoming barriers set by a certain reality. The overcoming of these barriers is the first step to overcoming the limits and realization of the "unprecedented-viable", which Freire proposes.
\end{abstract}

KEYWORDS: Pedagogy of the Oppressed; Paulo Freire; Reality; Hope.

\footnotetext{
${ }^{4}$ Adjunct Professor in the course of Nature Sciences Degree / UNIPAMPA. Doctor and Master of Education from the Federal University of Santa Maria. Pedagogue. E-mail: sandraufsmppge@gmail.com

${ }^{5}$ PhD in Brazilian Anthropophagy. Full Professor Federal University of Santa Maria / UFSM. LOL. E-mail: vbarcelos@terra.com.br
} 


\section{INTRODUÇÃO}

\subsection{Um homem, uma vida, um sonho...}

Não há educação fora das sociedades humanas e não há homem no vazio (Paulo Freire, 1981, Educação como prática da liberdade).

O homem que ficou reconhecido como um dos maiores educadores brasileiros e cidadão do mundo, Paulo Reglus Neves Freire (1921-1997), nasceu na cidade do Recife no dia 19 de Setembro do ano de 1921. Joaquim Temístocles Freire, seu pai, era capitão da Polícia Militar do Estado de Pernambuco. Sua mãe chamava-se Edeltrudes Neves Freire, carinhosamente chamada de Tudinha. Freire teve uma irmã de nome Stela, que foi professora primária, e dois irmãos: Armando e Temístocles. Freire sempre foi muito grato aos seus irmãos homens que, em função das condições econômicas precárias da família, não concluíram seus estudos básicos para começar muito cedo a trabalhar. Foram esses irmãos que proporcionaram a Freire a possibilidade de estudar e formar-se na Universidade. Freire casou-se duas vezes. A primeira esposa chamava-se Elza Freire (1944-1986), com quem teve cinco filhos. A segunda esposa foi Ana Maria Araújo (Nita Freire). Freire formou-se em Direito pela Universidade do Recife no ano de 1943. Contudo, abandonou a carreira muito cedo por sentir que essa profissão não lhe traria felicidade em função da distância entre a Justiça e o Direito. Começou então a carreira de professor no Ensino Médio, ensinando Língua Portuguesa. No ano de 1946, Paulo Freire foi convidado para o cargo de diretor do Departamento de Educação e Cultura do Serviço Social no Estado de Pernambuco. Foi a partir desse cargo que Freire dedicou-se, intensamente, ao trabalho com a alfabetização de jovens e adultos. Dedicou especial atenção ao trabalho com os mais pobres. Certamente que nem mesmo ele poderia imaginar a repercussão dessa decisão em sua vida.

Uma das consequências dessa decisão foi a dedicação à construção de uma proposta revolucionária de alfabetização de adultos pobres, em grande parte camponeses do interior do nordeste brasileiro. Com sua proposta ou "método" de alfabetização foi capaz de alfabetizar 300 adultos cortadores e cortadoras de cana-de-açúcar num curto período de 45 dias. O educador Paulo Freire acabou tornando-se uma referência e uma inspiração para muitas gerações de professores(as) no Brasil, na América Latina e no continente africano. Seu trabalho 


\section{$e$-Curriculum}

Programa de Pós-Graduação em Educação: Currículo

foi reconhecido nos cinco continentes. Recebeu o título de Doutor Honoris Causa nas maiores e mais prestigiadas universidades do mundo. Foram nada mais nada menos que 27 Títulos de Doutor Honoris Causa. Paulo Freire ganhou ainda prêmios como: Educação para a Paz (das Nações Unidas, 1986) e Educador dos Continentes (da Organização dos Estados Americanos, 1992).

Seu envolvimento com a alfabetização de adultos pobres, inevitavelmente, o levou a despertar desconfiança num primeiro momento e muito ódio em seguida. Sua proposta política de educação ia de encontro às propostas das elites e dos governos da época. Tal contexto o levou a várias prisões, a exílios e a todo tipo de tentativa de difamação. Até de "traidor da pátria" foi chamado por muitos integrantes da elite rica do país. Teve importante militância política, fazendo parte da primeira diretoria executiva da Fundação Wilson Pinheiro, que apoiava o Partido dos Trabalhadores (PT). Foi Secretário de Educação (1989-1992) da cidade de São Paulo na gestão da prefeita Luiza Erundina. Com o golpe militar de 1964, Paulo Freire foi preso por 70 dias em um quartel do exército, em Recife. Durante essa prisão aconteceram fatos pitorescos e que Freire gostava de narrar em suas conferências como forma de não ficar amargurado em excesso com as adversidades pelas quais passou. Freire era um sujeito bem humorado e que gostava de uma longa e calma conversa.

Paulo Freire morreu como viveu. Cheio de amorosidade com sua gente e de indignação com as injustiças e "malvadezas" dos poderosos e dos tiranos. Semeou bonitezas por onde passou. Freire fez legítima a máxima do poeta mexicano Octávio Paz (1914-1998), quando esse afirmava que se "Morrestes de forma diferente daquela que viveu, é sinal de que não foi tua a vida que vivestes". Era a madrugada do dia 2 de maio de 1997, às cinco e meia da manhã, quando sua passagem foi registrada no leito hospitalar onde estava internado.

\section{DESENVOLVIMENTO}

\subsection{Da realidade vivida à realidade sonhada}

"La realidad no es así, está aî". “A realidade não é assim, está assim". (Paulo Freire, O grito Manso, 2003).

O professor Celso de Rui Beisiegel encerra seu prefácio para a $60^{a}$ edição comemorativa do livro Pedagogia do Oprimido, publicada pela Editora Paz e Terra, no ano de 2016, da 
Programa de Pós-Graduação em Educação: Currículo

seguinte forma: "A qualidade, a riqueza e a generosidade das propostas e ideais que permeiam toda a sua obra encontram-se forte e claramente marcadas em Pedagogia do Oprimido" (BEISIEGEL, 2016, p. 31). Se os escritos de Freire, que antecederam a publicação do livro Pedagogia do Oprimido foram fundamentais para a concretização dessa obra, pode-se dizer que esse livro se esparramou, encharcou toda a produção freireana posterior a ela. Pedagogia do Oprimido foi como que um adensamento dos escritos de Freire até então. Agora Freire apresenta de forma incisiva, e mesmo radical, suas análises sobre as injustiças sociais numa sociedade de opressores e de oprimidos. O caráter político da obra freireana ganha, com Pedagogia do Oprimido, um impulso que não mais pode ser freado. Talvez essa tenha sido uma das motivações para tantos ataques que Freire e sua obra receberam ao longo do tempo de parte das elites reacionárias e dos defensores de uma educação elitista e discriminatória.

Se existe algo que pode ser considerado um consenso sobre a obra de Paulo Freire, tanto antes como após a publicação de Pedagogia do Oprimido, é a presença da sua preocupação com a realidade vivida dos homens e das mulheres na sociedade brasileira. Particularmente, com os grandes contingentes de abandonados à própria sorte pelas elites intelectuais e políticas do Brasil. Pensar a obra de Freire sem os brasileiros e brasileiras reais é algo definitivamente impossível. Não por acaso no livro Educação como Prática da Liberdade (publicado no Chile em 1965), livro que antecedeu o Pedagogia do Oprimido, Paulo Freire faz um esclarecimento introdutório em que escreve: "Não há educação fora das sociedades humanas e não há homem no vazio" (p. 35). Freire oferece esse livro - Educação como Prática da Liberdade - a todas as pessoas que no Brasil continuavam resistindo ao autoritarismo da época, bem como àqueles e àquelas que, como ele, tiveram de exilar-se em outros países. Sem esquecer-se de mencionar os que estavam sendo presos e torturados nos porões da ditadura militar que se instalou no Brasil pós-1964.

Paulo Freire fazia questão de ressaltar essa permanente preocupação com a realidade vivida pela sociedade brasileira quando se referia aos seus conterrâneos chamando-os de "minha gente". A expressão "gente", frequentemente utilizada por Freire, tinha uma conotação muito particular, tanto do ponto de vista sociológico e antropológico quanto pedagógico. Uma demonstração dessa importância, temos registrada quando Freire afirma, textualmente, que como educadores (as), não podemos nunca nos esquecer de que, em educação, lidamos com gente e não com coisas. Nas suas palavras: 


\section{e-Curriculum}

Lido com gente e não com coisas. E porque lido com gente, não posso, por mais que, inclusive, me dê prazer entregar-me à reflexão teórica e crítica em torno da própria prática docente e discente, recusar minha atenção dedicada e amorosa à problemática mais pessoal deste ou daquele aluno ou aluna (FREIRE, 1997, p. 32).

Essa admiração pelas gentes do Brasil foi sempre levada e demonstrada por Freire nos diferentes lugares onde trabalhou e viveu. Não escondia sua imensa paixão pelas gentes brasileiras, em especial, pelos marginalizados, pelos pertencentes às periferias excluídas pelas elites econômicas, intelectuais e acadêmicas. Não podemos esquecer que as elites brasileiras se mostraram - e ainda se mostram - uma das mais arrogantes e perversas do planeta. Para Freire, uma das formas de evitar cair nas armadilhas da arrogância e da prepotência, tão ao gosto de uma elite que vivia de costas para o Brasil real, era não esquecer, nunca, que o trabalho do educador numa sociedade tão injusta como a nossa, é um trabalho com gente. Novamente em suas palavras,

\footnotetext{
Gente em permanente processo de busca. Gente formando-se, mudando, crescendo, reorientando-se, melhorando, mas, porque gente, capaz de negar os valores, de distorcer-se, de recusar, de transgredir... Lido, por isso mesmo, independentemente do discurso ideológico negador dos sonhos e das utopias, com os sonhos, as esperanças tímidas, às vezes, mas às vezes, fortes dos educandos. Se não posso, de um lado, estimular os sonhos impossíveis, não devo, de outro, negar a quem sonha o direito de sonhar. Lido com gente e não com coisas (FREIRE, 1997, p. 144).
}

Essa vinculação tão estreita, tão encarnada nas pessoas reais e em suas vicissitudes cotidianas certamente teve importante papel no fato de seu livro Pedagogia do Oprimido - bem como toda sua obra - ter sido tão bem entendido em todos os continentes onde foi e ainda é lido, estudado, pesquisado e referenciado como obra atemporal. Um clássico, na melhor acepção que se possa dar a essa palavra. Freire e sua obra continuam atuais. No livro La voz Del Maestro, acerca de vivir, enseñar y transformar el mundo ${ }^{i i}$, publicado na Argentina pela editora Siglo Veinteuno (2018), reafirma a necessidade de buscarmos compreender o mundo que vivemos, o tempo em que vivemos para, assim, nos mantermos nele inseridos e não alienados. Freire, apesar de seus 72 anos, continuava se autodefinindo como uma pessoa que nunca desiste de refletir sobre as condições reais da vida real de sua gente. Nas suas palavras: "Soy um hombre de hoy" (FREIRE, 2018, p.17).

Pedagogia do Oprimido teve a influência das publicações anteriores de Freire, mas, também, de sua passagem pelo Serviço Social da Indústria (SESI) do Estado de Pernambuco. Freire assumiu a recém-criada Divisão de Educação e Cultura. Nas palavras do próprio Freire: “Campo de experiência, de estudo, de reflexão, de prática, se constituiu como um momento 
Programa de Pós-Graduação em Educação: Currículo

indispensável à gestação da Pedagogia do Oprimido" (FREIRE, 1992, p. 19). Freire resume a construção da Pedagogia do Oprimido ao escrever que "A Pedagogia do Oprimido não poderia ter sido gestada em mim só por causa de minha passagem pelo SESI, mas a minha passagem pelo SESI foi fundamental” (p. 18). De outra forma, Freire também coloca como de grande influência na construção de Pedagogia do Oprimido a sua tese intitulada Educação e Atualidade brasileira (1959), apresentada na Universidade Federal do Recife. Essa tese deu origem ao decisivo livro Educação como Prática da liberdade e esse se desdobra, em muito, em anunciar o que viria a ser a Pedagogia do Oprimido.

Vale lembrar que a primeira publicação de Pedagogia do Oprimido não foi na língua portuguesa e sim em inglês, no ano de 1970. Talvez esse fato tenha tido, também, grande importância para a ampla aceitação que o livro teve já à época. Publicado inicialmente em língua inglesa, em Nova York, logo foi traduzido para o espanhol, o italiano, o alemão, o holandês e o sueco (BEISIEGEL, 2018). Só em 1974 saiu a primeira edição brasileira pela editora Paz e Terra.

Com Pedagogia do Oprimido Freire fez o exercício fundamental para qualquer intelectual que mereça realmente essa denominação: partiu da busca do entendimento profundo da realidade vivida para construir a realidade sonhada. Esse exercício, pensamos que ele sintetizou, magistralmente, na expressão: "La realidad no es a si, está así” (“A realidade não é assim, está assim”).

No segundo capítulo do livro Pedagogia do Oprimido, Freire dedica uma densa reflexão sobre o que ele denomina de uma concepção "bancária" da educação. Essa concepção de educação, segundo Freire, está marcada por "relações que ele denomina de relações narradoras e dissertadoras" (FREIRE, 2016, p. 103). Esse tipo de relação se dá entre dois personagens, a saber: o sujeito, que corresponde ao narrador; e os objetos, que correspondem aos (às) educandos(as) que, como objetos, sua condição é de meros ouvintes ou coadjuvantes. É evidente nesse tipo de relação o interesse de manter o (a) educando (a) na passividade. Seu papel é de mero expectador e sua participação se resume à aceitação, assimilação e reprodução dos conteúdos "depositados" pelo narrador/dissertador, no caso em questão o educador. O processo educativo como se resume a um ato mecânico de narrar e narrar sobre uma dada realidade apresentada pelo educador ao educando. Realidade essa que não the pertence ou que da mesma o educando nada, ou muito pouco, teria a dizer. Vamos ao que sobre essa relação escreve Freire, para quem nessa perspectiva educacional o que acontece é: 


\section{$e$-Curriculum}

Falar da realidade como algo parado, estático, compartimentado e bem-comportado, quando não falar ou dissertar sobre algo completamente alheio à experiência existencial dos educandos, vem sendo, realmente, a suprema inquietação desta educação. A sua irrefreada ânsia. Nela, o educador aparece como seu indiscutível agente, como seu real sujeito, cuja tarefa indeclinável é "encher" os educandos dos conteúdos de sua narração (FREIRE, 2016, p. 104).

Com tal método o que se tem é um completo desprezo pelo (a) educando(a) e sua experiência vivida. Nega-se a esse(a) educando(a) sua própria condição de sujeito. A aprendizagem se resume a receber e assimilar, como seus, desde os conhecimentos apresentados pela via dos conteúdos até os valores culturais do narrador/dissertador. Assim que, os conteúdos que os(as) educandos(as) devem assimilar podem ser totalmente estranhos ao mundo vivido, ou seja, desconectados, estranhos a sua realidade. Com isso, a palavra veiculada nessa dissertação é uma palavra vazia, oca. Para Freire, o desfecho dessa prática é que a palavra, que deveria ser transformadora da realidade, se resume à mera sonoridade a ser assimilada pelo(a) educando(a). Fecha-se, assim, um círculo quase perfeito para uma relação de objetificação entre educador (a) e educando(a), pois, “Na visão bancária da educação, o 'saber' é uma doação dos que se julgam sábios aos que julgam nada saber" (FREIRE, 2016, p. 105).

Ao negar ao(à) educando(a) o direito de ter reconhecida sua capacidade, como sujeito humano, de entendimento do mundo em que vive comete-se um verdadeiro crime contra sua humanidade. $\mathrm{O}$ crime de desejar mantê-lo no mundo da alienação. Nessa prática educativa, o educador que consegue realizar seu objetivo será reconhecido como educador eficiente e sua prática educativa tida como eficaz. Já aos(às) educando(as) cabe o papel de aceitar docilmente seu lugar de mero objeto de uma educação bancária. Com isso realiza-se o objetivo da educação bancária, "Como um ato de depositar, em que os(as) educandos(as) são os depositários e o educador, o depositador" (FREIRE, 2016, p. 105). O saber que daí decorre deixa de ser o que Freire denomina de "saber da experiência feita", para se tornar em um saber de experiência narrada ou transmitida. A consciência crítica, tão importante num processo de educação libertadora, defendido por Freire em Pedagogia do Oprimido, fica relegada ao total desprezo.

A educação como uma janela para a inserção dos sujeitos no mundo, a partir do entendimento da realidade vivida, se transforma, simplesmente, em mais um mecanismo de dominação e de alienação. A condição de sujeitos de suas vidas lhes é tomada. O papel de transformação pela educação fica completamente anulado nessa perspectiva de educação bancária. Essa preocupação freireana, e essa compreensão política da necessidade de romper com o modelo de educação em que educados(as) são meros objetos da educação alienante, já 
se faz presente no livro Educação como Prática da Liberdade (1965), quando o autor alerta para a necessidade de uma educação para as amplas camadas da população brasileira excluídas do processo de participação na vida política e das riquezas produzidas no país. Riquezas, essas, decorrentes da exploração da força de trabalho em condições as mais precárias. Na primeira parte de Educação como Prática da Liberdade - intitulada Esclarecimentos -, escrita em Santiago do Chile (1965), Freire chama a atenção para a necessidade de uma educação que rompa com a perspectiva de educação "Para o homem-objeto" e se encaminhe para uma educação para o "homem-sujeito" (p. 37).

É esse homem e essa mulher, sujeitos de sua história, que são o sentido e objetivo de uma educação como prática da liberdade e da autonomia propostas por Freire. Paulo Freire não se cansava de alertar para o fato de que uma educação que mereça realmente essa denominação não pode esquecer-se que a realidade dos educandos e educandas não pode ser pensada sem sonhos, pois, até se pode pensar vida humana sem sonhos, jamais existência humana e histórica sem a boniteza de sonhar um mundo mais justo e fraterno. De outra forma, o papel do(a) educador(a) não é nunca, "Falar ao povo sobre nossa visão do mundo, ou tentar impô-la a ele, mas dialogar com ele sobre a sua e a nossa” (FREIRE, 2016, p. 146).

Como educadores(as) haveremos de estar cientes de que as visões de mundo, o entendimento da realidade dos educandos e educandas, nada mais são que as suas visões de mundo e que refletem, assim, "Sua situação no mundo, em que se constitui. A ação educativa e política não pode prescindir do conhecimento crítico dessa situação, sob pena de se fazer 'bancária' ou de pregar no deserto" (FREIRE, 2016, p.147). Como se pode perceber, é marcante na obra de Freire em geral, e na Pedagogia do Oprimido em particular, essa permanente preocupação com o diálogo entre educadores(as) e educandos(as). Diálogo esse que só será possível se realizar a partir da busca sincera e generosa de aproximação de educadores(as) e de educandos(as), tendo como ponto de partida a realidade dos segmentos populares. Para Freire, ou reconhecemos a necessidade de mergulhar junto com educandos(as) em sua realidade ou estaremos nos restringindo a simples portadores(as) de boas vontades e de discursos ocos.

Não por acaso o educador Ernani Maria Fiori (1914-1985) inicia o Prefácio de Pedagogia do Oprimido afirmando: "PAULO FREIRE É UM PENSADOR comprometido com a vida: não pensa ideias, pensa a existência” (FIORI, 1967, p. 34. Grifos do autor). Um pensador que, ao mesmo tempo em que vive o tempo presente, não descuida de atualizar o que já foi. Em Pedagogia do Oprimido, Freire falou a partir de 1968, mas continua contemporâneo naquilo 


\section{e-Curriculum}

Programa de Pós-Graduação em Educação: Currículo

que é sua maior substância: a busca de uma educação libertadora de homens e de mulheres no tempo em que vivem suas existências. Assim visto, faz jus ao que escreveu Freire ao se referir ao seu Pedagogia do Oprimido como um livro que não diz do que foi, mas, sim, um livro que está sendo.

\subsection{Da realidade vivida à realidade sonhada - sonho e utopia}

Amigo, se você veio aqui pensando que ia ensinar nós a derrubar o pau, nós tem de dizer a você que não tem precisão. Nós já sabe derrubar o pau. O que nós quer saber é se você vai tá com nós na hora do tombo do pau (FREIRE, 2003, p. 45).

No capítulo 4 do livro Pedagogia do Oprimido, ao tratar da Teoria da Ação Antidialógica, Paulo Freire afirma textualmente que: "Não há realidade histórica - mais outra obviedade - que não seja humana" (FREIRE, 2016, p. 203). As razões para isso seriam óbvias, pois, "Não há história sem homens, como não há uma história para os homens, mas uma história de homens que feita por eles, também se faz" (FREIRE, 2016, p. 204). Fica explícita, nessa formulação, que, para Freire, homens e mulheres não são objetos da história ou objetos a serem pesquisados, estudados pelas elites. Freire é enfático sobre essa condição ao afirmar que: “O mundo não é um laboratório de anatomia nem os homens são cadáveres que devam ser estudados passivamente" (FREIRE, 2016, p. 208). Interpretamos essa formulação freireana como uma forma de colocar homens e mulheres não na periferia, mas, sim, no centro do fazer da história. Assim tomado o papel de homens e mulheres, na realidade em que vivem, podemos afirmar que homens e mulheres além de fazerem parte da história podem assumir seus destinos e fazer, assim, a história mesma.

É com essa assunção de seu papel de "fazedores e fazedoras" da história que homens e mulheres passam da condição de "homem-objeto" para "homem-sujeito", como apontado por Freire em Pedagogia do Oprimido. Esse papel de donos de sua história é tão fundamental na obra freireana em geral, e, particularmente, na Pedagogia do Oprimido, que o educador faz questão de alertar, inclusive, para o risco de mesmo defensores de movimentos revolucionários tomarem os setores oprimidos como seus objetos de ação política. Sobre isso, em Pedagogia do Oprimido Freire é radical e alerta que "O humanista científico revolucionário não pode, em nome da revolução, ter nos oprimidos objetos passivos de sua análise, da qual decorrem prescrições que eles devam seguir" (FREIRE, 2016, p. 208). A maneira de evitar esse equívoco 
Programa de Pós-Graduação em Educação: Currículo

histórico e político é a liderança revolucionária, científica e humanista para evitar repetir a prática das elites dominadoras de levar às últimas consequências a ideia de ignorância das massas populares. Setores progressistas não podem, jamais, "Crer nesse mito. Não tem sequer o direito de duvidar, por um momento, de que isto é um mito" (FREIRE, 2016, p. 209).

Freire dedica uma longa reflexão sobre essa possibilidade em Pedagogia do Oprimido, certamente por temer a manipulação de suas "gentes" por parte de oportunistas e manipulares que acreditam que os fins justificam os meios de ação. Vamos a mais uma manifestação de Freire sobre essa questão fundamental. Para ele, nenhuma liderança pode admitir,

Que só ela sabe e que só ela pode saber - o que seria descrer das massas populares. Ainda quando seja legítimo reconhecer-se em um nível de saber revolucionário, em função de sua mesma consciência revolucionária, diferente do nível de conhecimento ingênuo das massas, não pode sobrepor-se a este, com o seu saber (FREIRE, 2016, p. 210).

Entendemos essa preocupação de Freire como mais uma demonstração de sua lucidez política e de sua capacidade de análise, já à época dos desfechos de embates no continente latino-americano, e mesmo no mundo, entre setores progressistas e setores reacionários autoritários. Freire traduz essa sua visão sobre o processo de libertação quando afirma textualmente que "Ninguém liberta ninguém, ninguém se liberta sozinho: os homens se libertam em comunhão" (FREIRE, 2016, p. 95). A libertação daqueles que se encontram em condição de subjugação não pode ser vista como uma libertação que vem de outro, que vem de fora. Para Freire, essa libertação precisa ser entendida como uma libertação de pessoas, pois, não podemos nos esquecer, nunca, que em educação estamos lidando com gente. Nas suas palavras: "Estamos lidando com homens e não com coisas. Por isso, se não é autolibertação - ninguém se liberta sozinho -, também não é libertação de uns feita por outros. Não se pode realizar com os homens pela 'metade'. E, quando o tentamos, realizamos a sua deformação" (FREIRE, 2016, p. 97).

A maneira mais direta de evitar-se que essa libertação seja mais um processo de "enganação" e não de verdadeira libertação é, para Freire, o caminho do diálogo. A opção pela busca de sua libertação deve ser uma opção consciente feita pelos oprimidos e não uma dádiva trazida por um "iluminado". Nesse sentido, a libertação proposta por Freire não é uma "Doação que lhes faça a liderança revolucionária, mas resultado de sua conscientização” (2016, p. 99). Isso pode parecer uma obviedade, contudo nem sempre é percebida pela liderança revolucionária. As camadas oprimidas precisam perceber por sua própria reflexão - e aí sim 


\section{$e$-Curriculum}

Programa de Pós-Graduação em Educação: Currículo

fazer sua opção consciente - a possibilidade de sua inserção na realidade vivida e, a partir dessa constatação, perceber que essa realidade pode, sim, ser por essas camadas transformada.

Com isso, seria dado o primeiro passo na direção da passagem da realidade vivida para a realidade sonhada. Como na epígrafe, que colocamos no início desse item, mais que a pretensão de "ensinar" ao outro - coisas que às vezes ele já sabe e não sabemos que ele sabe há que se estar junto a ele nas horas da "precisão". Como na fala do pequeno agricultor: "Nós já sabe derrubar o pau. O que nós quer saber é se você vai tá com nós na hora do tombo do pau" (FREIRE, 2003, p. 35). Esse estar junto na realidade vivida leva educando(a) e educador(a) a serem parceiros numa tarefa cooperativa. Nesse processo de estar junto, e cooperar, se encontram dois sujeitos e não um sujeito e um objeto. Em tal tipo de processo acontece aquilo que Freire busca em toda sua obra, e, em especial, em Pedagogia do Oprimido: sujeitos "cointencionados à realidade, se encontram numa tarefa em que ambos são sujeitos no ato, não só de desvelá-la e, assim, criticamente conhecê-la, mas, também, no de recriar este conhecimento" (FREIRE, 2016, p. 101). Ao partilharem essa ação, homens e mulheres "Alcançam, na reflexão e na ação em comum, este saber da realidade, se descobrem como seus refazedores permanentes" (p. 101).

Acrescentaríamos apenas: Fazedores(as) e refazedores(as) de sonhos e realizadores(as) de utopias. Artífices de seus “inéditos-viáveis", transformando a realidade que está assim, em uma realidade outra: uma realidade antes ousada ser sonhada.

\section{CONCLUSÃO}

\subsection{Algumas palavras de esperança}

No hay nada que esté fatalmente determinado en el mundo de La cultura... no hay fatalismo en la conducta humana... Hay que pelear (FREIRE, 2003, p. 78).

Paulo Freire dá início ao seu livro Pedagogia da Esperança - um reencontro com a Pedagogia do Oprimido relatando o assombro que algumas pessoas manifestavam em relação ao título do referido livro. Eram alguns colegas seus de universidade e até parceiros de engajamento na busca de uma educação libertadora. Conta que um colega seu de universidade assim manifestou sua surpresa: "Mas como, Paulo, uma Pedagogia da Esperança no bojo de uma tal sem-vergonhice como a que nos asfixia hoje, no Brasil?” (FREIRE, 1992, p. 09). 
Paulo Freire foi sempre um encantado com a educação. E esse encantamento se manifestava mesmo nas horas mais difíceis. Diga-se, que é nessas horas - difíceis -em que tudo parece desmoronar e que as alternativas desaparecerem, que a desesperança toma conta, que as pessoas raras têm seu papel histórico e político mais importante.

Freire foi uma dessas pessoas raras. Freire representou, da melhor maneira possível, a condição de um intelectual na sociedade em que viveu. Intelectual no sentido mais poderoso e generoso dessa expressão: aquele que busca entender o mundo e o tempo em que vive. Freire não se importava nem mesmo quando uns tantos faziam pouco ou o taxavam de ingênuo ao propor sonhos, ao defender utopias. Talvez, algo que ajudava a deixar seus críticos ainda mais desconcertados era a forma como Freire apresentava suas alternativas. O fazia com muita firmeza, porém, com uma ternura, uma boniteza que desarmava mesmo as mentes mais empedernidas, pelo menos em sua frente. Freire deixou marcas por onde passou. E não foram marcas quaisquer. Foram marcas profundas deixadas com doçura e com mansidão. Ele próprio mais de uma vez expressou que se considerava uma pessoa, um sujeito manso.

Freire nos deixou várias expressões muito fortes. Uma delas foi a do "inédito-viável". Em Pedagogia da Esperança (publicado duas décadas após Pedagogia do Oprimido), Freire evoca a necessidade de retomar-se a ideia do inédito-viável já proposta em Pedagogia do Oprimido, 20 anos antes. Freire quis mostrar que aquilo que parece ser uma impossibilidade numa dada situação ou condição, pode ser mudado. Situações que se apresentam como imutáveis nem sempre o são, haja vista o que já referenciamos anteriormente neste texto, quando Freire sentencia: a realidade não é assim, está assim!

Mais que uma frase de efeito, essa é, em verdade, um chamado à participação, um desafio a esperançar feito por Freire. Esperançar como verbo, justamente para reafirmar a necessidade do pensar crítico, da ação, da não aceitação das situações simplesmente como se apresentam. Para Freire, a existência humana se faz e refaz na esperança e no sonho. Freire não se cansava de reafirmar que sua esperança não era suficiente, mas, sim, necessária. Nas suas palavras:

Precisamos da esperança crítica, como o peixe precisa da água despoluída... Pensar que a esperança sozinha transforma o mundo e atuar movido por tal ingenuidade é um modo excelente de tombar na desesperança, no pessimismo, no fatalismo... É por isso que não há esperança na pura espera, nem tampouco se alcança o que se espera na espera pura, que vira, assim, espera vã (FREIRE, 1992, p. 11). 


\section{e-Curriculum}

Esse esperançar se faz ponto de partida para buscar realizar os sonhos, sem os quais, segundo Freire, não há existência humana. Freire deu uma importância muito grande para a proposição do "inédito-viável"ii em sua obra. Não por acaso retoma essa proposição, cunhada em Pedagogia do Oprimido, vinte anos depois em Pedagogia da Esperança - um reencontro com a Pedagogia do Oprimido. Faz essa retomada como forma de demonstrar a atualidade de Pedagogia do Oprimido décadas depois. Atualidade, essa, que entendemos ainda muito presente, cinquenta anos depois.

A atualidade de Pedagogia do Oprimido soa como um clamor, quando Freire escreveu: "Só existe saber na invenção, na reinvenção e na busca inquieta, impaciente, permanentemente, que os homens fazem no mundo, com o mundo e com os outros. Busca esperançosa também" (FREIRE, 2016, p. 105). Freire deposita suas esperanças no(a) educando(a) mais que em qualquer outra possibilidade. Esperança nesses educandos e educandas sujeitos de sua história, contudo, isso só acontece quando os(as) educandos(as) se fazem realmente, "Educando[s] quando e na medida em que conhece $[m]$, ou [vão] conhecendo os conteúdos, os objetos cognoscíveis, e não na medida em que o educador vai depositando nele[s] a descrição dos objetos, ou dos conteúdos" (FREIRE, 1992, p. 47).

A esperança a que se refere Freire não é uma esperança vã, mas, sim, um compromisso com a história vivida pelas gentes do Brasil. Essa esperança se fundamenta na crença freireana de que homens e mulheres são seres "inconclusos" e, como tais, seres em permanente transformação de si e das suas realidades. Em função dessa condição, Freire toma os seres humanos como seres que "estão sendo", seres do inacabamento. Como alerta Freire, a história é uma construção inacabada, e tendo a história como uma construção radicalmente humana, a realidade também é uma construção permanente, portanto, inacabada.

A educação num tal cenário é algo que está o tempo todo se refazendo. Nas palavras de Freire, a educação como "Um quefazer permanente. Permanentemente, na razão da inconclusão dos homens e do devir da realidade... Dessa maneira a educação se re-faz constantemente na práxis. Para ser tem que estar sendo" (FREIRE, 2016, p. 127).

Essa é uma das diferenças fundamentais entre uma educação bancária e uma educação libertadora. Enquanto a primeira busca a acomodação, a mesmice, a repetição dos conteúdos, a segunda deseja e busca ativamente a reflexão, a ação, a problematização das dificuldades, a superação das barreiras interpostas por uma dada realidade. A superação dessas dificuldades e 
Programa de Pós-Graduação em Educação: Currículo

barreiras é o primeiro passo para a superação dos limites e realização do "inétido-viável" que propõe Freire.

Quando nos encontramos com os colegas professores(as), tanto da Educação Básica quanto das universidades, ainda percebemos, tristemente, como se faz presente a opção - às vezes consciente outras inconsciente - por práticas educativas de uma educação bancária. Cinquenta anos após Pedagogia do Oprimido ser escrito e publicado percebe-se como suas contribuições ainda se fazem ausentes em muitas situações reais, de nossas escolas reais, de nossos educandos e educandas reais.

Essa constatação, contudo, não deve servir para nos desesperançar. Ao contrário, deve ser um estímulo a mais no sentido de nos inquietar, de nos fazer refletir sobre a realidade brasileira e, assim, nos movimentar na direção de uma educação que seja mais parecida com a cara miscigenada das gentes do Brasil. Das gentes de Pindorama.

Vida longa à Pedagogia do Oprimido, em seus 50 anos de existência entre educadores e educadoras desse tão maltratado país. País onde a "malvadeza" das elites reacionárias - como gostava de dizer Freire - insiste em produzir injustiças. Com esse sincero texto que ora oferecemos aos possíveis leitores e leitoras, não queremos muito, porém, queremos um pouco.

Um pouco de diálogo, um pouco menos de intolerância entre homens e mulheres, um pouco de esperança, um pouco de alegria no fazer docente, um pouco de generosidade entre as pessoas.

Enfim, damos uma pausa neste texto, parafraseando Paulo Freire na sua última frase do Pedagogia do Oprimido, 50 anos atrás: queremos um mundo onde seja um pouco "menos difícil AMAR".

\section{REFERÊNCIAS}

BEISIEGEL, Celso de Rui. In prefácio à $60^{a}$ edição comemorativa do livro Pedagogia do Oprimido. Rio de Janeiro: Paz e Terra, 2016.

FREIRE, Paulo. Pedagogia da esperança: um reencontro com a Pedagogia do oprimido. Rio de Janeiro: Paz e Terra, 1992.

Educação como Prática da liberdade. Rio de Janeiro: Paz e Terra, 1992.

Pedagogia da Autonomia: saberes necessários à pratica docente. Rio de Janeiro: Paz e Terra, 1997.

Política e Educação. São Paulo: CORTEZ, 2003. 
El grito manso. Buenos Aires: Siglo Veintiuno, 2003.

Pedagogia do Oprimido. Rio de Janeiro: Paz e Terra, 2016.

La voz Del maestro. Acerca de vivir, enseñar y transformar el mundo.

Conversaciones con Edson Passetti. Buenos Aires: Siglo Veintiuno, 2018.

Notas:

${ }^{\text {i }}$ Originalmente publicado com o título de Conversação Libertária com Edson Passetti. São Paulo,1998. Editora Imaginário.

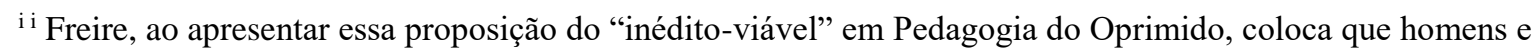
mulheres se defrontam em sua existência com obstáculos e dificuldades. A essas dificuldades Freire denomina de "situações-limites". Segundo o educador, a ação frente a essas situações-limites pode ser de aceitação, mas, também, de enfrentamento. As pessoas que optam pela segunda alternativa são aquelas que vão em busca da realização de seus sonhos, da viabilização de suas utopias. É essa busca que poderá alcançar o que Freire denominou, em Pedagogia do Oprimido, de "inédito-viável”. 